\section{Risk factors for intradomiciliary infestation by the Chagas disease vector Triatoma dimidiata in Jutiapa, Guatemala}

\author{
Factores de riesgo para la infestación intradomiciliaria \\ por el vector de la enfermedad de Chagas, \\ Triatoma dimidiata, en Jutiapa, Guatemala
}

\section{${ }^{1}$ Facultad de Ciencias Químicas y Farmacia, Universidad de San Carlos de Guatemala, Ciudad de Guatemala, Guatemala. 2 Facultad de Ingeniería, Universidad de San Carlos de Guatemala, Ciudad de Guatemala, Guatemala. 3 Área de Salud de Jutiapa, Ministerio de Salud Pública y Asistencia Social, Ciudad do Guatemala, Guatemala. \\ Correspondence C. Monroy Laboratorio de Entomología Aplicada y Parasitología, Escuela de Biología, Facultad de Ciencias Químicas y Farmacia, Universidad de San Carlos. \\ Edificio T-10, 2do Nivel, Ciudad Universitaria, Zona 12, Ciudad de Guatemala, Guatemala. \\ carlotamonroy@yahoo.com cmonroy@usac.edu.gt}

\begin{abstract}
Seventeen variables were evaluated as possible risk factors for the intradomiciliary infestation with Triatoma dimidiata in 644 houses in Jutiapa, Guatemala. During 2004 the houses were assessed for vector presence and evaluated for hygiene, cluttering, material comfort, construction conditions and number of inhabitants, among other factors. Chi-square analysis detected significant associations between vector presence and eight variables related to domestic sanitary and construction conditions. Log-linear models showed that regardless of the age of the house, the odds of vector presence were 4.3 and 10 times lower in houses with a good socioeconomic status compared with poor and very poor houses respectively. Log-linear models also pointed to a greater chance of vector presence when walls lacked plastering (3.85 times) or walls had low quality-incomplete plastering (4.56 times), compared with walls that were completely plastered. Control strategies against $\mathrm{T}$. dimidiata should include the introduction of better-quality but inexpensive plastering formulations and better sanitation practices should also be promoted among the population. Such control strategies should not only reduce or eliminate infestation, but also prevent vector reinfestation.
\end{abstract}

Triatoma; Chagas Disease; Vector Control; Risk Factors
Dulce Maria Bustamante 1

Carlota Monroy 1

Sandy Pineda 1

Antonieta Rodas ${ }^{1}$

Xochitl Castro 1

Virgilio Ayala 2

Javier Quiñónes ${ }^{2}$

Bárbara Moguel 1

Ranferi Trampe 3

\section{Introduction}

Triatoma dimidiata is the most important vector of Chagas disease in Guatemala, El Salvador, Nicaragua and Costa Rica, and it is of secondary importance in Honduras and Colombia 1. Across its distribution from Mexico to Colombia, Venezuela, Ecuador and Peru, this species can be found in both wild and domestic ecotopes ${ }^{2}$. In nature the species has been found in warm weather, in dry or humid forests, and from sea level to about 2,000 meters above sea level. Its natural micro-environments include caves, palm trees, rock piles, hollow trees, and opossum nests, among others 1 . In areas where Chagas disease is endemic, T. dimidiata can generally be found in rural houses and peridomestic structures. Similar to other triatomines that form domestic colonies, this species hides in cracks in earthen walls (adobe), under loose plaster, behind furniture, behind pictures or other wall ornaments, and under bed mattresses when these are present 2 .

To the best of our knowledge the only published study that has evaluated risk factors for house infestation by $T$. dimidiata was carried out in Costa Rica ${ }^{3}$, where houses with poor sanitary conditions, dirt floors, and tile roofs were more commonly infested. But using a multivariate loglinear model, the authors found that only roof type was a significant risk factor for infestation while the other factors in the model (sanitary condition, floor type, and firewood indoors) 
were found to be non-significant ${ }^{3}$. In Guatemala, prior vector surveys point to rural houses with walls made from earthen or vegetal materials (bajareque) to be more commonly infested with T. dimidiata $4,5,6$.

Evidently, the hygiene and construction conditions of rural houses that make them suitable for triatomine infestation are directly linked to socioeconomic status and cultural practices. For example, in rural areas of Morelos, Mexico, T. pallidipennis was more likely to be present in houses with adobe walls and with agricultural products stored inside the house; other risk factors included the lack of bed nets and number of rabbits 7. But in urban areas of Morelos, the risk factors included the location of the house at lower altitudes (which was an indication that houses were of a lower socioeconomic status), the presence of a garden area of more than $80 \mathrm{~m}^{2}$, an adjacent empty lot, and the presence of a diversity of animals around the house (dogs, pigs, squirrels, opossums) 8 .

In the present study we wanted to evaluate a set of variables that were indicators of the hygienic and construction conditions in the house, cultural practices, and socioeconomic status, as possible risk factors for intradomiciliary infestation by $T$. dimidiata in the southwestern department of Jutiapa, Guatemala. This department had been previously identified with the highest infestation levels in the country and has a well documented history of re-infestation after chemical spraying 6,9,10.

The present risk factors study was conduced as part of a larger project regarding the evaluation of the effectiveness of a participative and multidisciplinary approach 11 to control T. dimidiata in Jutiapa. The identification of risk factors served as the foundation to develop interventions to control the vector that did not require overly expensive modifications to the houses or the introduction of unfamiliar cultural practices, thus facilitating the involvement of the people in the affected communities in the control of the vector.

\section{Materials and methods}

\section{Study site}

Four villages in the department of Jutiapa were selected to conduct this study: El Tule and La Brea in the Municipality of Quesada, and El Sillon and La Perla in Yupiltepeque Municipality. Both municipalities share similar socioeconomic backgrounds that we consider representative of the entire department.
The Municipality of Quesada is located in western Jutiapa. In the most recent national census 12 this municipality had a population of 17,869 with $99.6 \%$ of the people belonging to the Ladino ethnic group, which is the denomination given in Guatemala to people of mostly European descent or people who come from a mixed background (Mayan, European) but have lost Mayan cultural practices and speak almost exclusively Spanish. According to the census there were a total of 4,446 accommodation facilities (houses, apartments, improvised houses, etc.) in this municipality in 2003, of which $78 \%$ had adobe walls and $18 \%$ had block walls. Most roofs were covered with tiles $(51 \%)$ or galvanized metal sheet (45\%).

The Municipality of Yupiltepeque is located in eastern Jutiapa. In 2002 it had a population of 13,079 of which $86.7 \%$ were Ladinos and $13.2 \%$ Xinca (a non-Mayan indigenous ethnic group). There were a total of 3,142 accommodation facilities with $78 \%$ of those having adobe walls and $13 \%$ having block walls. The roofs were mostly made from galvanized metal sheets $(64 \%)$ and tiles (32\%).

Almost all of the population in both municipalities was Spanish speaking (99.7\% in Quesada; 99.8\% in Yupiltepeque) and a relatively large proportion of the population aged seven and above had basic formal education $(76 \%$ in Quesada, $67.6 \%$ in Yupiltepeque). In Quesada $41.1 \%$ of the population above the age of seven was economically active (ie in employment) while this proportion was 37\% in Yupiltepeque. Among those working, $52.3 \%$ and $86.6 \%$ were involved with agriculture in Quesada and Yupiltepeque, respectively. Quesada had a more diverse job market and the second most important activity was personal, communal and social services (19\%).

\section{Survey methods}

In 2004, entomological and house condition surveys were conducted in a total of 644 houses from the four villages. Five teams formed by two people conducted the surveys: one of them was a member of the research team and the other one was a technician from Jutiapa's Health Department. At the moment of the visit, the people present in the house were asked for their consent to search inside the house for triatomines and were invited to help the surveyors fill out a form with some general information about the house and its inhabitants.

Once they orally agreed to collaborate, the surveyors searched inside the house for triatomines for a half hour, using flashlights to inspect walls, under bed mattresses, and behind furni- 
ture or any other object placed in the walls. All evidence of vector presence was recorded: live or dead triatomines, exuviae's specimens, eggs, or fecal streaks. After the entomological inspection various aspects of house conditions were assessed visually by one of the surveyors and recorded in standardized forms. Gathered information included the number of inhabitants, number of beds, presence of electricity, potable water, outhouse (bathroom), bathing customs, place for firewood storage, kitchen location (inside in bedroom or as a separate room), presence of domestic animals inside the bedrooms and occurrence of mice inside the house. Surveyors also registered data on house's material comfort, hygiene, and cluttering. Information about construction materials and plastering conditions of each wall in the house was also gathered.

The housing aspects evaluated as risk factors were selected based on our previous experiences in the area and on risk factors reported for Costa Rica 3 . Most of the factors were variables directly evaluated by surveyors that did not rely heavily on information provided by inhabitants (except for house age, animals, and mice inside the house). Although many of the variables were stable through relatively long periods of time (wall materials or roof type), some were more dynamic (place of firewood storage, number of inhabitants) and this could undermine finding associations with vector presence.

Based on the information gathered, houses were classified in three categories according to quality of living conditions to represent the socioeconomic status of the house. Category A houses were prosperous, had electro domestic appliances and the best combination of hygienic and house construction conditions: plastered walls and cement floors in all rooms. Category B houses were poor, had few or no electro domestic appliances, with poor hygiene (cluttering), with regular house construction conditions: unplastered walls or plasters in bad conditions and dirt floors in some areas throughout the house. Category $\mathrm{C}$ houses were catalogued as very poor, had no electro domestic appliances, very precarious hygienic conditions (cluttering, animals inside the house), generally with bad house construction: bedrooms with dirt floors and with most of the walls without plaster or only partially plastered.

\section{Statistical analysis}

Villages were similar in housing construction practices and culture, thus information from the four was considered together for the evaluation of risk factors. The interest was to determine which factors could explain the presence of the T. dimidiata in the houses. Because the villages under study had been previously sprayed at least once, it was difficult to find live bugs at the moment of the survey. Thus for this analysis, a house was considered positive for vector presence if either live insects or its products (dead insects, exuviae, eggs, and fecal streaks) were found by surveyors. In defining the variable this way, vector absence could be a result of live bugs or its products not being present in the house (either true or due to cleaning) or failure to detect them.

Seventeen variables were evaluated for possible associations with presence of $T$. dimidiata in a house (Table 1). Some quantitative variables were aggregated to transform them into categorical (qualitative) variables. This was the case for house age, number of windows, number of house inhabitants, number of beds, and number of people per bed.

Chi-square tests of independence were conducted to evaluate associations between $T$. dimidiata presence and each of the 17 variables (alpha for the tests was 0.05). Where independence was not supported by the chi-square test, adjusted residual analysis was conducted. Under independence adjusted (adjr) residuals fall between $-2 \leq \operatorname{adjr} \leq+2$, thus values outside this range indicate either significantly negative or positive trends 13 .

Further analysis using log-linear models allowed the study of the associations between two variables, while controlling for the effects of a third one 13 . The variables were used in each of the four models constructed (Table 2).

The variable "house category-house age" was created to evaluate associations between vector presence and house construction conditions (floor, walls, plastering) while controlling for house age and category. Older, poorer and untidier houses could be more likely to have exuviae or fecal streaks than newer, prosperous and/or cleaner houses. The new variable was constructed by combining the levels of the two original variables, resulting in 9 levels (3 house categories*3 house ages). For instance, the first two levels were "category A house, 0 to 6 years old", "category B house, 0 to 6 years old", and so forth.

Models were fitted using the PROC GENMOD procedure in SAS (SAS Inst., Cary, United States) with Poisson distributed errors and log links. The models fitted were homogeneous associations that included the three variables and all their twoway interactions. Fit assessment was performed by the deviance statistic that approximates a chisquare distribution. A good fit of this model to the data indicates significant associations among the three variables. 
Characteristics of the houses surveyed in Quesada and Yupiltepeque, Jutiapa, Guatemala.

\begin{tabular}{|c|c|c|}
\hline Variables & Total & $\%$ * \\
\hline Surveyed houses & 644 & 100.0 \\
\hline Houses with $T$. dimidiata presence & 199 & 30.9 \\
\hline \multicolumn{3}{|l|}{ House category } \\
\hline A (Prosperous) & 155 & 24.1 \\
\hline B (Poor) & 193 & 30.0 \\
\hline C (Very poor) & 293 & 45.5 \\
\hline \multicolumn{3}{|l|}{ Wall construction materials } \\
\hline Adobe & 431 & 66.9 \\
\hline Block & 75 & 11.6 \\
\hline Mixed (adobe-block) & 94 & 14.6 \\
\hline Other materials & 41 & 6.4 \\
\hline \multicolumn{3}{|l|}{ Wall plastering condition } \\
\hline Complete & 207 & 32.1 \\
\hline Low quality and/or incomplete & 274 & 42.5 \\
\hline No plastering & 132 & 20.5 \\
\hline \multicolumn{3}{|l|}{ House age (years) } \\
\hline $0-6$ & 270 & 41.9 \\
\hline $7-18$ & 168 & 26.1 \\
\hline$\geq 19$ & 177 & 27.5 \\
\hline \multicolumn{3}{|l|}{ Floor type } \\
\hline Dirt or earthen & 367 & 57.0 \\
\hline Other types of flooring & 261 & 40.5 \\
\hline \multicolumn{3}{|l|}{ Roof type } \\
\hline Galvanized metal sheet & 419 & 65.1 \\
\hline Tile & 195 & 30.3 \\
\hline Other types of roofing & 16 & 2.5 \\
\hline \multicolumn{3}{|l|}{ Kitchen } \\
\hline Inside & 263 & 40.8 \\
\hline Outside & 364 & 56.5 \\
\hline \multicolumn{3}{|l|}{ Firewood storage } \\
\hline Kitchen (inside) & 64 & 9.9 \\
\hline Kitchen (outside) & 102 & 15.8 \\
\hline Hall around house & 189 & 29.3 \\
\hline Bedroom & 27 & 4.2 \\
\hline Yard & 212 & 32.9 \\
\hline \multicolumn{3}{|l|}{ Number of windows in bedroom } \\
\hline None & 291 & 45.2 \\
\hline 1 & 245 & 38.0 \\
\hline$\geq 2$ & 55 & 8.5 \\
\hline \multicolumn{3}{|l|}{ Number of people per house } \\
\hline $1-4$ & 267 & 41.5 \\
\hline $5-8$ & 300 & 46.6 \\
\hline$\geq 9$ & 74 & 11.5 \\
\hline \multicolumn{3}{|l|}{ Number of beds per house } \\
\hline $1-2$ & 185 & 28.7 \\
\hline $3-4$ & 329 & 51.1 \\
\hline$>4$ & 116 & 18.0 \\
\hline \multicolumn{3}{|l|}{ Number of people per bed } \\
\hline$\leq 1$ & 163 & 25.3 \\
\hline $1<x \leq 2$ & 322 & 50.0 \\
\hline$>2$ & 144 & 22.4 \\
\hline
\end{tabular}

(continues) 


\begin{tabular}{lcc} 
Table 1 (continued) & Total & $\%$ * \\
\hline Variables & & 23.4 \\
\hline $\begin{array}{l}\text { Animals present inside bedroom } \\
\quad \text { Number of houses }\end{array}$ & 151 & \\
Mice present inside bedroom & & 70.7 \\
(as indicated by inhabitants) & 455 & 55.1 \\
$\quad$ Number of houses & 355 & 86.8 \\
Potable water in household & & \\
$\quad$ Number of houses & 559 & 52.8 \\
Electricity in household & & \\
$\quad$ Number of houses & 340 & 61.5 \\
Outhouse or bathroom present & & 5.1 \\
$\quad$ Number of houses & 396 & 19.3 \\
Bathing facilities & 33 & 7.8 \\
$\quad$ Stored water or hose & 124 & \\
$\quad$ Public water tank & 50 & \\
$\quad \begin{array}{l}\text { Shower } \\
\text { River }\end{array}$ &
\end{tabular}

* Totals (percentages) do not add up to 644 (100\%) due to missing data.

Table 2

Variables used to fit four log-linear models to study the associations between variable 1 and variable 2 (variable 3 ) controlling for variable 3 (variable 2).

\begin{tabular}{lllc}
\hline Model & Variable 1 & Variable 2 & Variable 3 \\
\hline 1 & T. dimidiata presence & House category & House age \\
2 & T. dimidiata presence & House category-house age & Floor type \\
3 & T. dimidiata presence & House category-house age & Wall plastering conditions \\
4 & T. dimidiata presence & House category-house age & Wall construction materials \\
\hline
\end{tabular}

\section{Results}

Among the 644 houses in the four villages, 199 (30.9\%) had positive presence of $T$. dimidiata (Table 1). Approximately one fourth of households $(24.1 \%)$ were classified by us as category A or prosperous. Thirty percent of households were considered category B, with inhabitants that were poor but tended to keep a tidier house, while $45.5 \%$ of households were considered category $\mathrm{C}$, very poor households with mostly unhygienic, cluttered, and inadequately constructed houses.

Chi-square analysis detected significant associations between vector presence and 8 out of 17 variables (Table 3). Most of those variables involved house sanitary and construction conditions (which facilitate shelter for the bugs). Adjusted residuals analysis indicated that vector presence tended to occur more often in category
C houses $($ adjr $=6.49)$, with adobe walls $($ adjr $=$ $4.64)$, with low quality or incomplete plastering $($ adjr $=6.08)$, with dirt floors $(\operatorname{adjr}=5.53)$, with animals inside the bedroom (adjr $=3.00$ ) and mice inside the house (adjr $=3.00)$. On the other hand, vectors were less frequent in houses less than 6 years old (adjr $=-5.06$ ), with two or more windows in the bedroom (adjr $=-3.01$ ), and with indoor bathing facilities (shower; adjr = -3.89).

The four log-linear models studied showed a good fit for homogeneous associations, as indicated by their deviance values (Table 4 ). The first model evaluated associations among $T$. dimidiata presence, house category, and house age. When controlling for house age, the odds of vector presence in category A houses were 4.34 and 10 times lower than those for category B and C houses, respectively. Also, the odds of presence in category B houses were 2.32 times lower than 
Associations between T. dimidiata presence and house variables surveyed in Quesada and Yupiltepeque, Jutiapa, Guatemala.

\begin{tabular}{|c|c|c|c|}
\hline Variables & $\chi^{2}$ & Degrees of freedom & $\mathrm{p}$-value \\
\hline House category & 54.07 & 2 & $<0.0001$ \\
\hline Wall construction materials & 36.17 & 3 & $<0.0001$ \\
\hline Wall plastering conditions & 59.89 & 2 & $<0.0001$ \\
\hline House age & 26.01 & 2 & $<0.0001$ \\
\hline Floor type & 30.64 & 1 & $<0.0001$ \\
\hline Roof type & 3.90 & 2 & 0.14 \\
\hline Kitchen & 0.19 & 1 & 0.66 \\
\hline Firewood storage & 4.05 & 4 & 0.40 \\
\hline Number of windows in bedroom & 9.06 & 2 & 0.01 \\
\hline Number of people per house & 1.02 & 2 & 0.60 \\
\hline Number of beds per house & 3.98 & 2 & 0.14 \\
\hline Number of people per bed & 3.19 & 2 & 0.20 \\
\hline Animals inside bedroom & 9.45 & 1 & 0.002 \\
\hline Mice inside bedroom & 8.45 & 1 & 0.004 \\
\hline Drinking water & 0.50 & 1 & 0.48 \\
\hline Electricity & 1.55 & 1 & 0.21 \\
\hline Outhouse or bathroom & 4.74 & 1 & 0.05 \\
\hline Bathing facilities & 16.46 & 3 & 0.001 \\
\hline
\end{tabular}

for category C. When controlling for house category, the odds of vector presence in houses six years old or less were 3.44 times lower than for houses 7-18 years old, and 3.57 times lower than for houses 19 years or older.

The second log linear model indicated that $T$. dimidiata presence and floor types were conditionally independent, at each house category-age level. In other words, when each of the nine levels of house category-age was considered separately, there was no evidence for an association between floor type and vector presence. This differs from the univariate analysis result where these variables were significantly associated.

The third log linear model showed that at any level of the house category-age combination, the odds of $T$. dimidiata presence were not different between houses with no plastering versus those with low quality or incomplete plastering. However, unplastered houses did have 3.85 times higher odds of infestation than completely plastered houses. Similarly, low quality or incomplete plastering increased the odds of infestation 4.56 times compared to a complete plastering.

Finally, the fourth log linear model indicated that at any level of the house category-age combination, the odds for T. dimidiata presence were 9.55 times higher in adobe houses versus block houses, and 14.13 times higher in houses made from mixed materials versus block houses. There were no differences in odds among other types of house construction, except for reduced odds in houses made from other materials (like wood) versus mixed adobe-block (2.78 times lower).

\section{Discussion}

The present analysis provided evidence that poor socioeconomic status, precarious house conditions and poor hygiene practices in Jutiapa are associated with higher odds of intradomiciliary infestation with T. dimidiata. Many of the variables studied independently were inherently correlated because, for example, dirt floors were more common in houses with unplastered adobe walls, or indoor bathrooms and showers were related to prosperous houses (category A). An understanding of these correlations is important for our interpretation of the results.

Vector occurrence and poor hygiene were positively associated as indicated by a positive trend of bug presence in category $\mathrm{C}$ houses, with animals and mice inside the bedroom, and a negative association with indoor bathing facilities (more common in houses category A). Observations in the field lead us to conclude that in poorer houses (with lower incomes and fewer formally educated inhabitants) people will tend to allow poultry to nest inside the house and will 
Associations between presence of Triatoma dimidiata and house category, age, floor, walls, and plastering.

\begin{tabular}{|c|c|c|c|c|}
\hline Model (deviance; df) & Controlling for & Odds ratio between & Parameter estimate & $95 \%$ confidence limits \\
\hline \multirow[t]{9}{*}{$1(4.11 ; 4)$} & House age & The odds of $T$. dimidiata & & \\
\hline & & presence in houses category: & & \\
\hline & & A vs. B & 0.23 * & $0.12-0.46$ \\
\hline & & A vs. C & 0.10 * & $0.05-0.19$ \\
\hline & & B vs. C & 0.43 * & $0.28-0.66$ \\
\hline & House category & $\begin{array}{l}\text { The odds of } T \text {. dimidiata } \\
\text { presence in houses of: }\end{array}$ & & \\
\hline & & (0-6) vs. $(\geq 19$ years old) & 0.29 * & $0.18-0.47$ \\
\hline & & (7-18) vs. $(\geq 19$ years old $)$ & 1.03 & $0.64-1.67$ \\
\hline & & (0-6) vs. (7-18 years old) & 0.28 * & $0.18-0.46$ \\
\hline \multirow[t]{4}{*}{$2(4.95 ; 8)$} & House category and age & The odds of $T$. dimidiata & & \\
\hline & & presence in houses with: & & \\
\hline & & Dirt floor vs. other & & \\
\hline & & types of flooring & 1.41 & $0.84-2.40$ \\
\hline \multirow[t]{8}{*}{$3(15.77 ; 16)$} & House category and age & The odds of $T$. dimidiata & & \\
\hline & & presence in houses with: & & \\
\hline & & No plastering vs. & & \\
\hline & & Low quality and/or incomplete & 0.84 & $0.51-1.41$ \\
\hline & & No plastering vs. & & \\
\hline & & complete plastering & 3.85 * & $1.92-7.71$ \\
\hline & & Low quality and/or incomplete vs. & & \\
\hline & & complete plastering & 4.56 * & $2.52-8.25$ \\
\hline \multirow[t]{9}{*}{$4(16.67 ; 24)$} & House category and age & The odds of $T$. dimidiata & & \\
\hline & & presence in houses with & & \\
\hline & & walls made of: & & \\
\hline & & Adobe vs. block & 9.55 * & $2.05-44.46$ \\
\hline & & Adobe vs. mixed & 0.68 & $0.38-1.19$ \\
\hline & & Adobe vs. other materials & 1.86 & $0.78-4.48$ \\
\hline & & Mixed vs. block & $14.13^{*}$ & $2.88-69.34$ \\
\hline & & Other materials vs. block & 5.12 & $0.90-29.24$ \\
\hline & & Other materials vs. mixed & $0.36^{*}$ & $0.13-0.98$ \\
\hline
\end{tabular}

df: degrees of freedom.

* Odds ratio is significantly different from 1 .

perform thorough cleanings less often, creating suitable conditions for triatomine infestation. Changing socioeconomic conditions is not a realistic short-term approach to controlling Chagas disease vectors, but improving sanitation in the house is achievable and can have a positive effect in reducing vector presence while promoting healthier overall lifestyles. Zeledon \& Rojas 14 concluded that sanitary (and construction) improvement of the house creates conditions that difficult $T$. dimidiata infestation. In an anthropologic study conducted simultaneously as part of our transdisciplinary approach for Chagas control, hygienic practices were evaluated in more detail in order to identify the best approach to promote improved sanitation in accordance with local culture.

The assignment of houses into a particular category (A, B or C) relied partially on house construction conditions; thus, after finding a highly significant association between house category and vector presence, the same was expected for construction variables. Wall materials, plastering conditions, house age, floor type, and number of windows were all identified as risk factors in the univariate analysis. The lower risk of vector presence in houses with two or more windows in the bedroom could be related to T. dimidiata's preference for hiding in dark places. If windows are open daily and bright light enters the rooms, 
this could help deter the vectors from establishing colonies in those houses as long as the hiding places are reached by the light.

Because T. dimidiata presence (as defined here) could be intrinsically higher in the older or less often cleaned houses by accumulation of fecal streaks, exuviae or other signs, it was considered important to evaluate some of the associations among vector presence and construction variables, controlling for house category and age by using log-linear models.

The models supported that, regardless of house category or age, adobe houses or those with mixed block-adobe walls and low quality or incomplete plastering, had increased odds of bug infestation. Although rebuilding houses with blocks could extremely reduce infestation risks, this approach is unrealistic in the existing socioeconomic situation. However, provisioning houses with a complete plastering of higher quality and durability could be a more attainable approach to control vectors and it could have an impact similar to new block walls. A follow up study by engineers in our research team determined the way inhabitants perform house improvements with emphasis on plastering, and investigated local materials to formulate an improved and inexpensive plastering formulation.

Our statistical models did not support dirt floors as a risk factor for T. dimidiata in Guatemala, as it has been suggested for Costa Rica ${ }^{3,15}$. However, we believe that this factor needs further evaluation, possibly performed in locations where bug populations are increasing and forming colonies. The dust in the floors is used by nymphs of this species to camouflage 14,15 and this behavior could have survival advantages for the bugs.

Reduction or elimination of intradomestic T. dimidiata and the prevention of reinfestation are the priorities for Chagas control across the distribution of this vector. Different areas should evaluate their particular risk factors, but as studies throughout the years have evidenced the poor hygiene and the defective construction of typical rural houses, which are linked to low socioeconomic status, are the common denominators that increase odds of infestation with various triatomine species $3,7,8,16,17$.

When risk factors are targeted to eliminate intradomestic vectors, those same improvements will also help prevent reinfestation after chemical spraying. A study in Argentina that followed up the reinfestation of houses by T. infestans 16 found evidence that the number of bugs in a household previous to insecticide spraying and the surface conditions of indoor walls were significant domestic risk factors for reinfestation. Thus improving the indoor walls' conditions could have reduced the risk of reinfestation in that case. In addition to house construction improvements, people should be empowered with information to protect themselves against sporadic vectors entering houses; frequent thorough cleaning and better sanitation would also increase protection because bugs will be detected during the day and eliminated.

The present study successfully provided us with evidence that supported our transdisciplinary approaches for the control and prevention of intradomiciliary infestations. Insecticide spraying continues to be a very effective approach to reduce the populations of bugs (and other nuisance invertebrates like scorpions, cockroaches and fleas) and is generally well received by the population. Complementary control efforts must be prioritized in category $\mathrm{C}$ houses that have poor hygiene, deficient construction, and inhabitants of low socioeconomic status and low education. These complementary approaches must include better wall plastering and sanitation of the house. 


\section{Resumen}

Seiscientas cuarenta y cuatro casas en Jutiapa, Guatemala fueron encuestadas en el año 2004 para buscar el vector de la enfermedad de Chagas Triatoma dimidiata. Diecisiete variables relacionadas con las condiciones estructurales y de higiene de las casas fueron registradas y evaluadas como factores de riesgo para la infestación intradomiciliar con T. dimidiata. Análisis chi-cuadrado detectaron asociaciones significativas entre la presencia del vector y 8 de estas variables. En modelos log-lineares se detectó, que sin importar la antigüedad de la casa, las posibilidades de presencia del vector fueron 4,3 y 10 veces más bajas en casas con un buen estado socioeconómico que en casas pobres o muy pobres, respectivamente. Además, las posibilidades de infestación fueron mayores en casas con paredes sin repello (3,85 veces) o con repellado incompleto o de mala calidad (4,56 veces), que con repellado completo. Las estrategias para el control de T. dimidiata deberían incluir la introducción de repellos baratos y de buena calidad y la promoción de mejores prácticas sanitarias. Estas estrategias no solo reducirían o eliminaría la infestación, sino también ayudaría a prevenir la reinfestación.

Triatoma; Enfermedad de Chagas; Control Vectorial; Factores de Riesgo

\section{References}

1. Dorn PL, Monroy C, Curtis A. Triatoma dimidiata (Latreille, 1811): a review of its diversity across its geographic range and the relationship among populations. Infect Genet Evol 2006; 7:343-52.

2. WHO Expert Committee on the Control of Chagas Disease. Control of Chagas disease. Second report of the WHO Expert Committee. Geneva: World Health Organization; 2002. (WHO Technical Report Series, 905).

3. Starr MD, Rojas JC, Zeledon R, Hird DW, Carpenter TE. Chagas' disease: risk factors for house infestation by Triatoma dimidiata, the major vector of Trypanosoma cruzi in Costa Rica. Am J Epidemiol 1991; 133:740-7.

\section{Contributors}

D. M. Bustamante contributed on study design, data analysis and interpretation, and manuscript preparation. C. Monroy contributed on study design, data acquisition, and manuscript preparation. S. Pineda collaborated on data analysis, data acquisition, and manuscript arrangement. A. Rodas contributed on data analysis and tables formation. X. Castro collaborated on data analysis and tables construction. J. Quiñónez contributed on data acquisition and manuscript corrections. B. Moguel collaborated on data acquisition, reading and correcting the manuscript. V. Ayala collaborated on study design and correcting the manuscript. R. Trampe contributed on mainly field work and data collection.

\section{Acknowledgments}

We are grateful to the people in all the villages for welcoming us and collaborating in this study. We highly appreciate the hard work of all the members of the research team and the support of the personnel at Jutiapa's Health Department. Thank you to the reviewers whose input highly improved this manuscript. This work was supported by the International Development Research Centre (IDRC) under its "Ecosystem Approaches to Human Health Program Initiative”, Project 101812. Special thanks to Leonicio Revolorio for his contribution to the fieldwork.
4. Monroy C, Mejia M, Rodas A, Rosales R, Horio H, Tabaru Y. Comparison of indoor searches with whole house demolition collections of the vectors of Chagas disease and their indoor distribution. Medical Entomology and Zoology 1998; 49: 195-200.

5. Monroy C, Rodas A, Mejia M, Tabaru Y. Wall plastering and paints as methods to control vectors of Chagas disease in Guatemala. Medical Entomology and Zoology 1998; 49:187-93.

6. Tabaru Y, Monroy M, Rodas A, Mejia M, Rosales R. The geographical distribution of vectors of Chagas disease and populations at risk of infection in Guatemala. Medical Entomology and Zoology 1999; 50:9-17. 
7. Enger KS, Ordonez R, Wilson ML, Ramsey JM. Evaluation of risk factors for rural infestation by Triatoma pallidipennis (Hemiptera: Triatominae), a Mexican vector of Chagas disease. J Med Entomol 2004; 41:760-7.

8. Ramsey JM, Alvear AL, Ordonez R, Munoz G, Garcia A, Lopez R, et al. Risk factors associated with house infestation by the Chagas disease vector Triatoma pallidipennis in Cuernavaca metropolitan area, Mexico. Med Vet Entomol 2005; 19:219-28.

9. Nakagawa J, Hashimoto K, Cordon-Rosales C, Juares JA, Trampe A, Marroquin L. The impact of vector control on Triatoma dimidiata in the Guatemalan department of Jutiapa. Ann Trop Med Parasitol 2003; 97:289-98

10. Hashimoto K, Cordon-Rosales C, Trampe A, Kawabata $\mathrm{M}$. Impact of single and multiple residual sprayings of pyrethroid insecticides against Triatoma dimidiata (Reduviiade; Triatominae), the principal vector of Chagas disease in Jutiapa, Guatemala. Am J Trop Med Hyg 2006; 75:226-30.

11. Lebel J. Health. An ecosystem approach. Ottawa: International Development Research Centre; 2003.

12. Instituto Nacional de Estadística. Censos nacionales XI de población y VI de habitación. Ciudad de Guatemala: Instituto Nacional de Estadística; 2003.
13. Agresti A. An introduction to categorical data analysis. New York: John Wiley \& Sons; 1996.

14. Zeledon R, Rojas JC. Environmental management for the control of Triatoma dimidiata (Latreille, 1811), (Hemiptera: Reduviidae) in Costa Rica: a pilot project. Mem Inst Oswaldo Cruz 2006; 101:379-86.

15. Zeledon R, Vargas LG. The role of dirt floors and of firewood in rural dwellings in the epidemiology of Chagas' disease in Costa Rica. Am J Trop Med Hyg $1984 ; 33: 232-5$.

16. Gürtler RE, Petersen RM, Cecere MC, Schweigmann NJ, Chuit R, Gualtieri JM, et al. Chagas disease in north-west Argentina: risk of domestic reinfestation by Triatoma infestans after a single community-wide application of deltamethrin. Trans R Soc Trop Med Hyg 1994; 88:27-30.

17. De Andrade ALS, Zicker F, De Oliveira RM, Da Silva IG, Silva SA, Andrade SS, et al. Evaluation of risk factors for house infestation by Triatoma infestans in Brazil. Am J Trop Med Hyg 1995; 53:443-7.

Submitted on $17 / \mathrm{Dec} / 2007$

Final version resubmitted on 31/Mar/2008

Approved on 09/Apr/2008 